\title{
A NOÇÃO DE PIETAS NAS PRÁTICAS RELIGIOSAS DE RUDENS
}

\author{
Fellipe Duarte da Silva Alves de Souza* \\ Fernanda Messeder Moura* \\ (Universidade Federal do Rio de Janeiro)
}

\begin{abstract}
RESUMO: Neste artigo, aborda-se como a noção de pietas vem explorada comicamente por Plauto em Rudens, obra cuja ação é permeada pela religiosidade romana, em especial, do culto público. Com esse objetivo, abordamos a noção de pietas como vínculo social e religioso, levando em consideração o uso de pius e scelestus, a utilização cênica do templo, o lugar religioso que o mar assume em Rudens e a menção explícita a instrumentos utilizados no culto a Vênus. Considerando parte da problemática que envolve os conceitos de religião e religiosidade na Roma do período helenístico (FUNARI, 1993; Id., 2009; TOLLIVER, 1952) bem como o tratamento cômico fortemente ligado ao cotidiano no corpo plautino (DUCKWORTH, 1952) fazemos uma análise histórico-literária de fatos pertinentes para o estudo da prática religiosa, que é elemento essencial da cidadania romana coletiva que adveio da invenção da urbs (SCHEID, 1998). A conclusão a que chegamos é a de que Plauto representa a pietas na comédia a que se restringe este artigo, sobretudo por elementos cênicos e orais, de modo que a religiosidade se mostra intimamente ligada à correção de costumes observáveis nas personagens tipo.
\end{abstract}

PalaVras-ChaVe: Plauto; Rudens; religiosidade.

\section{THE NOTION OF PIETAS IN THE RELIGIOUS PRACTICES OF RUDENS}

\begin{abstract}
In this article, we deal with how the notion of pietas has been comically explored by Plauto in Rudens, a work whose action is permeated by Roman religiosity, especially by public worship. To this purpose, we treat the notion of pietas as a social and religious bond, taking into account the use of pius and scelestus, the scenic use of the temple, the religious place that the sea assumes in Rudens and the explicit mention of instruments that are used in the cult of Venus. Taking into account part of the problematic that involves the concepts of religion and religiosity in Rome in the Hellenistic period (FUNARI, 1993; Id., 2009; TOLLIVER, 1952) as well as the comic treatment that is strongly linked to everyday life in the Plautine corpus (DUCKWORTH, 1952) we made a historical analysis of literature based on facts that have proven to be relevant to the study of religious practice, which is an essential element of collective Roman citizenship that came from the invention of urbs (SCHEID, 1998). The conclusion we reached is that Plautus puts forth the notion of pietas in the comedy to

\footnotetext{
* Mestrando em Letras Clássicas da UFRJ, com bolsa da CAPES. E-mail: fellipe.duarte.sa@gmail.com

** Orientadora. E-mail: fernandamesseder@letras.ufrj.br
} 
which this article is restricted, mostly by the use of scenic elements and speeches, so that religiosity is intimately linked to the correction of observable customs in stock characters.

KEYWORDS: Plautus; Rudens; religiosity.

\section{Introdução}

Dentre os períodos históricos de Roma, o período helenístico, costumeiramente delimitado entre os anos 323 a.C. e 31 a.C. ${ }^{1}$, é aquele que apresenta a primeira grande efervescência cultural verificável na sociedade romana, como resultado de anos de conquistas bélicas. Os contatos entre Roma e povos vizinhos ou dominados que são verificáveis, com alguma clareza, desde o séc. IV (GRENIER, 1938, p.88) resultaram em mudanças nas práticas do romano, dentre elas as religiosas, fato reconhecível, por exemplo, na tentativa de proteção do mos maiorum e das práticas religiosas compreendidas nestes costumes pelo Senado republicano (GRENIER, 1938, p.197).

Uma vez que as fontes não-textuais de períodos anteriores ao séc. II a.C. são escassas na atualidade ${ }^{2}$, faz-se necessária e valiosa a relação entre literatura e história reconhecida em estudos relativamente recentes (e.g. LEENHARDT; PESAVENTO, 1998). Em tais estudos a literatura é apresentada como uma fonte que é constituída por processos semelhantes aos do discurso historiográfico com o qual compartilha o fito de representar a experiência. No caso de Plauto, autores como Duckworth (DUCKWORTH, G. E.. The nature of Roman Comedy. Princeton: Princeton University, 1952) argumentaram bem a respeito do fato de que este conhecia a tônica do cotidiano romano e a representava.

Titus Maccius Plautus (230-180 a.C) é um dos primeiros autores da literatura formal romana, contemporâneo de Quinto Ênio (239-169 a.C.), autor dos Anais, e antecessor do comediógrafo Terêncio (190-159 a.C. $)^{3}$. Na atualidade estão conservadas ao todo vinte peças de Plauto, todas consideradas autenticamente de sua autoria, segundo o critério de Varrão ( DUCKWORTH, 1952, p. 52). Como comediógrafo, este apresentava em suas obras as ações consideradas piores que as dos homens representados ${ }^{4}$ e, desse modo, não tinha a pretensão de apresentar grandes feitos, mas, provocar o riso e educar por meio de situações dramáticas com as quais o romano identificava-se e divertia-se.

Nesse sentido, ainda que as obras de Plauto sejam palliatae inspiradas na Comédia Nova, peças compostas de personagens gregos, que usam o pallium, e ambientação helênica, não há exclusivamente características gregas na composição destas, mas, também, romanas. Afinal, caso Plauto simplesmente adaptasse as obras gregas artificialmente, como a identificação do espectador seria possível? Este fazia uso dos moldes gregos ${ }^{5}$ ao participar ativamente da formação de uma literatura

\footnotetext{
${ }^{1}$ Cf. VEYNE, Paul. L'hellénisation de Rome et la problématique des acculturations. Diogène, 1979, pp. 3-29.

${ }^{2}$ Cf. SCHEID, John. La religion des romains. 3. ed. Malakoff: Armand Colin, 1998, p.19.

${ }^{3}$ Cf. MARTINS, Paulo. Literatura Latina. Curitiba: IESDE, 2009, pp. 24, 115 e 194.

4 "É também essa diferença o que distingue a tragédia da comédia: uma se propõe imitar os homens, representando-os piores; a outra os torna melhores do que são na realidade" (ARISTÓTELES, Arte poética, p. 3).

${ }^{5}$ No período em que se inicia a literatura formal em Roma, com a publicação da obra de Lívio Andronico, na Grécia já estavam estabelecidos gêneros literários complexos como, por exemplo, a poesia, o drama,
} 
verdadeiramente romana. Assim, a realidade do romano, certamente, era contemplada na composição das obras de Plauto e, também no aspecto da realização formal, como declara Duckworth (1952, p.20): "Plauto preservou em suas peças características do drama popular italiano, e muitos dos elementos das farsas atelanas"6.

Em The nature of Roman comedy (DUCKWORTH, 1952), o autor, ao tratar das comédias latinas, reconhece a fartura de referências da realidade do cidadão romano presentes nas obras de Plauto (DUCKWORTH, 1952, p. 5.). A condição do escravo no período helenístico, o modo como se davam as relações entre pai e filho, estigmas que existiam, o relacionamento do homem com a divindade, dentre outras questões são exemplos destes dados da realidade aludidos em Plauto. Portanto, Duckworth afirma: "O historiador da antiguidade pode, outrossim, encontrar nas comédias de Plauto numerosas alusões à vida do povo romano, bem como costumes e eventos"7

A escolha de temáticas realistas nas comédias latinas, por exemplo, característica que advém da Comédia Nova grega, é um fato que reforça a relação entre a literatura republicana e a realidade histórica do período. A respeito da Comédia Nova grega, Duckworth afirma o seguinte: "A ação da peça propriamente [...] não deriva de fontes trágicas mas da comédia primitiva e da vida contemporânea" ${ }^{\circ}$. A vida contemporânea, assim, é fator constituinte da comédia em que Plauto se baseou.

Assim, mesmo que a comédia de Plauto tenha como característica personagens que são verdadeiras caricaturas de vícios e virtudes, os tipos, o leitor associava estas críticas positivas ou negativas a condutas identificáveis na realidade. Isto, ainda que estas não sejam diretamente ligadas pelo poeta a figuras da sociedade (MARTINS, 2009, p. 113). O rufião Lycus, por exemplo, desonesto, explorador e enganador, contém já em seu nome a dica, por assim dizer, de seu caráter. "Lycus" significa "lobo" em grego.

Além das comédias de cenário e temática realistas havia comédias de temática mitológica, como, por exemplo, Amphitruo, que trata do engano da parte de Júpiter e Mercúrio que resulta no nascimento de Hércules. Estas eram menos popularidades do que as comédias de temas cotidianos, como indica o maior número de exemplares de obras deste último tema conservadas. Apenas Amphitruo das obras remanescentes de Plauto é de temática mitológica (DUCKWORTH, 1952, p. 24). Assim, segundo Duckworth (1952, p. 23):

Peças de temática mitológica eram populares, mas cada vez mais a ação passou a lidar com a vida cotidiana e recorrentemente estava centrada em uma história de amor. A respeito das personagens, em adição aos tipos familiares (maridos, esposas, filhos, escravos), o parasita, o soldado, a cortesã apareceram com maior frequência. ${ }^{9}$ (DUCKWORTH, 1952, p.23).

Admitirmos que os aspectos cotidianos da Roma helenística permeiam a comédia plautina de forma indissociável torna o estudo destas relações natural, uma vez que

a épica (DUCKWORTH, G. E. The nature of Roman Comedy. Princeton: Princeton University, 1952 , p. 3 e 4$)$.

${ }^{6}$ Duckworth (1952, p.20): "Plautus preserved in his plays features of Italian popular drama, and many of the elements of Atellan farces".

${ }^{7}$ Duckworth, 1952, p.5: "The ancient historian, furthermore, can find in the comedies of Plautus numerous references to Roman life and customs, and events".

${ }^{8}$ Id., p.35: "The action of the play itself [...] derives not from tragic sources but from earlier comedy or contemporary life".

${ }^{9}$ Duckworth, 1952, p.23: "Plays on mythological themes were popular, but more and more the action dealt with everyday life and often centered about a love story. As to characters, in addition to family types (husbands, wifes, sons, slaves), the parasite, the soldier, the courtesan appeared more frequently". 
Plauto intencionalmente produziu suas obras de maneira mirando seus espectadores. Suas peças são fonte tanto das práticas religiosas do cotidiano romano aludidas (DUCKWORTH, 1952) como da interpretação dessa realidade social depreendida pelo poeta (LEENHARDT; PESAVENTO, 1998). A respeito dos aspectos originalmente gregos presentes nas comédias plautinas, é pertinente a afirmação de Hanson (HANSON, Plautus and Roman religion, 1959, p. 50):

Ao fim da carreira dramática de Plauto, a religião romana, assim como a cultura romana em geral, já era um híbrido complexo [...] Se cortarmos tudo que é possivelmente de origem grega de um documento do segundo século a.C., nós falsificaremos o quadro da sociedade daquele século ${ }^{10}$

Assim, a heterogeneidade era característica constituinte da sociedade romana do período helenístico, especialmente com relação a aspectos da cultura grega.

Neste artigo, temos, pois, por objetivo tratar da religiosidade ítala em sua manifestação pública conforme representada numa das obras de Plauto em que são marcantes as influências do período helenístico, Rudens, de modo a enfocar o aspecto virtuoso da noção de pietas, levando-se em consideração uma parcela das problemáticas que envolvem a dicotomia religião e religiosidade no período estudado, sobretudo no modo como o romano relacionava-se com o divino (TOLLIVER, The state gods of Rome, 1952) a partir do que podemos depreender da obra selecionada. Assim sendo, são perguntas desta investigação: Como Plauto representa a pietas romana nas obras Rudens? Há relação entre a expressão da virtude pietas e o relacionamento do cidadão para com seus compatriotas (PEREIRA, 2002)? Essas e outras questões compõem os problemas que serão tratados neste artigo.

\section{Considerações sobre religião e religiosidade em Roma}

Antes de tratarmos diretamente do conceito de religiosidade em Roma, parece-nos produtivo discutir a problemática que envolve a categorização de uma religião romana. Seria, no contexto da Roma helenística, a religião uma opção? Suas práticas envolviam, necessariamente, sentimento religioso? Um romano pius seria estritamente aquele que presta culto aos deuses?

TOLLIVER, 1952, afirma que doze divindades eram cultuadas desde a época arcaica e perpetuaram-se nos períodos seguintes como deuses estatais: Júpiter, Juno, Netuno, Minerva, Marte, Vênus, Apolo, Diana, Vulcano, Vesta, Mercúrio e Ceres. Tais deuses, no culto público, estavam a cargo de oficiais, o qual era exercido "pelos magistrados - sacerdotes, comandantes e homens públicos a uma só vez" (FUNARI, 1993, p.18). Estas cerimônias públicas não eram uma ação governamental que tinha por objetivo apresentar opções ao cidadão, mas, o vir romanus tinha a obrigação de participar destas cerimônias para que evitasse qualquer suspeita de traição ao Estado romano:

Uma vez que a aderência a esta religião estatal era parte do dever do cidadão e ele dificilmente poderia negar os deuses nacionais sem aparentar ser um traidor, sua atitude para com eles era

\footnotetext{
${ }^{10}$ Hanson, 1959, p.50: "By the end of Plautus dramatic career, Roman religion, like Roman culture in general, was already a complex hybrid [...] If we cut everything that is possibly Greek in origin from a second century B.C. document, we are falsifying the picture of that century's society".
} 
manifestadamente uma questão de importância [...] Deve ser esclarecido que a palavra "religião" no seu sentido corrente dificilmente poderia ser aplicada ao sentimento do povo romano pelas suas deidades estatais, já que para o cidadão comum estes eram provavelmente mais próximos da natureza de símbolos nacionais a serem reverenciados, possivelmente, do mesmo modo que a nossa bandeira. ${ }^{11}$ (TOLLIVER, 1952, p.49)

Os deuses do culto oficial, na Roma helenizada, eram figuras estritamente ligadas ao Estado romano. Sua importância como símbolos nacionais na sociedade contemporânea a Plauto era tamanha que é possível afirmar que a "religião romana" tratava-se de uma obrigação cívica do cidadão. Contudo, acreditamos que seria precipitado afirmarmos que via de regra não havia um sentimento religioso para com a divindade, ainda que possamos concordar que a existência deste sentimento não era determinante para a existência da prática religiosa em Roma.

A respeito da importância das deidades em Roma, TOLLIVER (loc. cit.) afirma: "eles e seus ritos postulados eram importantes vínculos entre o indivíduo e seu governo. Em altíssimo nível esta religião estatal intensificava o patriotismo" ". Assim, é válido destacarmos que no contexto helênico a prática religiosa era entendida como um elo entre o cidadão e a cidade.

SCHEID, 1998, concorda que um fato influenciador determinante na religião romana historicamente conhecida é a invenção da $U r b s$. Todas as práticas religiosas e sociais do romano tinham por base a coletividade: "Veremos que esse ideal de vida coletiva determinava a maioria dos aspectos da prática e do pensamento religioso [...] a religião romana em sua forma histórica foi constituída na época da invenção da cidade" ${ }^{13}$. Portanto, o romano que tinha por qualidade a pietas cumpria seus deveres não só para com os deuses mas, também, para com seus compatriotas e familiares. Esta virtude aliada à fides foram determinantes na congregação de povos sob o domínio de Roma (PEREIRA, M. H. R.. Idéias morais e políticas dos romanos in Estudos de história e cultura clássica. Lisboa: Fundação Calouste Gulbekian, 2002, p.325).

Tendo isso em vista, é pertinente o comentário de FUNARI, 2009, sobre a religiosidade:

a religiosidade, a fé característica da humanidade, está na raiz seja das religiões institucionalizadas, seja de todo movimento humano em prol de algo pelo que se luta, com crença profunda (uma religião, uma causa, uma crença). As manifestações religiosas são, pois, tão múltiplas e variadas como é diverso o ser humano, em suas inúmeras culturas, do presente e do passado (FUNARI, P.P.A (org.). As religiões que o mundo esqueceu: como egípcios, gregos, astecas e outros povos cultuavam seus deuses. São Paulo: Contexto, 2009, p.6)

\footnotetext{
${ }^{11}$ Tolliver (1952, p.49): "Since adherence to this state religion was part of a citizen's duty and he could hardly deny the national gods without appearing a traitor, his attitude toward them was manifestly a matter of importance [...] It should be noted here that the word "religion" in its current sense can hardly be applied to the Roman's feeling for his state deities, since for the ordinary citizen these were probably more in the nature of national symbols to be revered in perhaps somewhat the same way as our flag".

${ }^{12}$ Id. (loc.cit.): "they and their stablished rites were important ties between the individual and his government. On the highest level this state religion intensified patriotism".

${ }^{13}$ SCHEID, John. La religion des romains. 3. ed. Malakoff: Armand Colin, 1998, p.26: "Nous verrons que cet idéal de vie collective détermine la plupart des aspects de la pratique et de la pensée religieuse [...] la religion romaine sous sa forme historique s'est constituée à l'époque de l'invention de la cité".
} 
Esta força impulsionadora de difícil definição está presente há séculos em todas as sociedades humanas (FUNARI, op.cit., p.5). Especificamente a respeito do modo como o romano lidava com a religiosidade, FUNARI, 1993, afirma algo que complementa estas considerações:

Os romanos eram muito religiosos, mas num sentido muito especial da palavra: consideravam o respeito aos rituais como fundamental para a manutenção da vida em sociedade. Esse tipo de religiosidade significava a crença na origem fabulosa de ritos cuja observância era de importância vital. (FUNARI, 1993, p.15)

Os ritos, práticas religiosas, eram, portanto, para o cidadão romano um meio de manter a harmonia da nação. Esta era a crença que o impulsionava a dedicar-se aos deuses que serviam. O desconhecimento de tais práticas e de sua importância em Roma implica desconhecer a essência da cidadania romana.

Dessa forma, o problema inicial da análise da prática religiosa do período em que as obras de Plauto estão inseridas está no fato de que as fontes não-literárias anteriores ao século II a.C. são escassas, restritas a descobertas arqueológicas e textuais de difícil compreensão ${ }^{14}$. Nesse sentido, uma análise histórico-literária a partir das evidências textuais deixadas nas peças de Plauto mostra-se uma alternativa valiosa.

Por ser até certo ponto questionável a pertinência da classificação de uma religião em Roma, consideradas as diversas manifestações de culto público e privado, podemos afirmar com mais segurança que as práticas religiosas, parte constituinte do cotidiano ítalo, e a necessidade de um relacionamento piedoso para com aqueles que o cercam, parte constituinte da religiosidade do vir, são observáveis em todas as obras do corpo plautino $^{15}$. Neste artigo, dedicaremos nossa atenção exclusivamente a Rudens.

\section{Práticas religiosas em Rudens}

Rudens $^{16}$ é uma obra de Plauto de temática cotidiana cuja ação se passa na costa de Cirene, durante as Afrodisíacas, festa religiosa em honra à deusa Vênus. A trama desvela temas recorrentes: Dêmones é um ancião ${ }^{17}$ ateniense que teve suas duas filhas raptadas quando crianças e, sem suas posses, se muda para a costa de Cirene. Também em Cirene está o rufião Lábrax na posse das jovens Palestra e Ampelisca e o jovem Plesídipo, apaixonado por Palestra. Este jovem faz um acordo com o rufião e dá uma parte do pagamento por ela como garantia, contudo, um siciliano chamado Charmides vem de encontro com o detentor das escravas posteriormente e o convence a levá-las para a Sicília. Desconsiderado o acordo com Plesídipo, estes partem em viagem, mas, por intervenção da estrela Arturo, a embarcação naufraga. As jovens sobrevivem e perdidas na costa vão de encontro ao templo de Vênus, onde se refugiam sob os cuidados da sacerdotisa que o preside. Lábrax e Charmides ao chegarem em terra firme

${ }^{14}$ Cf. Scheid (1998, p. 19): “ Il est extrêmement difficile de dépasser le II siècle av. notre ère. De l'époque archaïque proprement dite, on ne possède qu'une poignée de textes épigraphiques difficiles et surtout des sources archéologiques. Il n'est guère étonnant que les historiens suivent souvent la vision anachronique que les Romains eux-mêmes donnent de ces périodes reculées.", e, mais recentemente, Rüpke, Jörg (2016, p. 33) atestou o mesmo: "Relevant Latin sources are scarce before the first century BCE".

${ }^{15}$ É curioso ressaltar que esta compreensão romana de pietas é semelhante ao "resumo da Lei e dos profetas" presente em Mateus 12:30-31 que trata do amor a Deus e ao próximo.

${ }^{16}$ Segundo DUCKWORTH (1952, p.53), Rudens tem por base uma comédia de Dífilo.

${ }^{17}$ Cf. MOURA, F. M.. Análise tipológica do senex em Plauto: Periplectomenvs (Miles Gloriosvs) e Lysidamvs (Casina). Rio de Janeiro: UFRJ, 2005. 
tentam reaver as meninas a força, as quais são protegidas por Dêmones e Plesídipo, que descobrem seus paradeiros com a ajuda do escravo deste último: Tracálio. Ao usar uma corda o escravo de Dêmones, Gripo, consegue reaver do mar uma bolsa que contém joias que comprovam o nascimento livre das meninas que são, na verdade, filhas do ancião ateniense. Como desfecho, a mão de Palestra é dada a Plesídipo, o pai das meninas faz uma proposta pacífica a Lábrax e o escravo Gripo é liberto. Como veremos a seguir, por meio desta obra podemos ter contato com a representação plautina de diversas práticas religiosas do culto público, dentre as quais destacamos a dicotomia entre pius e scelestus, de modo diferente daquele já tratado por Champeaux (1989), instrumentos usados para sacrifícios, dentre outros elementos essenciais para o estudo da religiosidade.

São reveladores os versos 26 e 27 do prólogo de Rudens no que concerne à visão do romano do período helênico da postura para com os ritos:

\section{Facilius si qui p̌řs est a dis supplicans,} quam qui scèlēstǔst, inveniet veniam sibi.

Se é piedoso aquele que suplica aos deuses, terá mais fácil resposta para si do que quem é ímpio.

(PLAUTUS. Rudens, v. 26-27, grifo nosso)

Neste trecho, que tem como voz a estrela Arturo, observamos como aquele que é suplicante aos deuses deve ser zeloso para com a virtude pietas, dado especialmente pertinente quando confrontamos as acepções dos vocábulos destacados. SARAIVA, 1927, traz, em seu verbete correspondente, a informação de pius como "justo, que cumpre o dever, que presta o culto devido aos deuses, piedoso, pio" (SARAIVA, 1927, p.903). No caso de scelestus, por sua vez, a significação é a de "criminoso, ímpio, desgraçado" (id., ibid., p.1069). Tais acepções parecem confirmar o fato de que a religiosidade, no contexto plautino, era um dever do vir romanus, que acreditava garantir o favor dos deuses pela sua devoção ${ }^{18}$, uma vez que pius pode ser entendido como alguém zeloso para com o cumprimento do dever. Champeaux, em seu estudo sobre o elemento público e privado concernente à pietas romana (CHAMPEAUX, Jacqueline. «Pietas » : piété personnelle et piété collective à Rome. In: Bulletin de l'Association Guillaume Budé, n.3, octobre 1989), propõe, a partir de Rudens, a seguinte distinção ao abordar o par pius-scelestus:

um sistema de equivalências e de oposições precisa e enriquece essas noções religiosas e morais: o pius é oposto ao scelestus e identificado ao homem de bem, aos boni que vivem cum pietate et cum fide, os que têm a pureza e coração e que, por si mesmos, podem obter o favor dos deuses. Pietas, pius, ganham um sentido novo. A pietas, tradicionalmente entendida como o estado da "boa relação com os deuses", se define pela retidão da intenção, não mais pela exatidão dos gestos. O homem "pio" não é mais somente aquele que

\footnotetext{
${ }^{18}$ A tratar da prática religiosa romana na declaração da guerra, FUNARI, 1993, afirma: "Tratava-se, assim, de estabelecer um contrato com os deuses garantindo seu apoio ao lado romano, contra o inimigo [...] Os gestos formais eram mais importantes do que os motivos reais, e os romanos "compravam" (ou ganhavam) os deuses mais do que os temiam" (FUNARI, op. cit., p.17).
} 
escrupulosamente satisfaz aos ritos; é "quem respeita os valores morais". ${ }^{19}$ (CHAMPEAUX, 1989, p.270).

De fato, é curioso observar que a postura contrária à pietas, segundo a acepção já apresentada, é representada comicamente por Plauto por meio do adjetivo scelestus, adjetivo derivado etimologicamente de scelus, sceleris (crime) ${ }^{20}$. Tal qualificação de ilegalidade para com os deuses não é surpreendente se considerarmos a importância, anteriormente exposta, da prática religiosa na manutenção da coletividade romana.

Em seu tratamento da questão, Champeaux (ibid, pp. 271-272) expande assim a noção de pietas:

Um estudo das ocorrências [...] de toda essa família de palavras, pietas-impietas, pius-impius, em Plauto, permite reconhecer nele três formas - ousaremos dizer três níveis? - de pietas. A primeira, sem dúvida a mais primitiva, é ritual, formal, sacrificial. Ela está de todo imbuída no culto externo dos deuses. É aquela a que evocava a estrela Arcturo: donis, hostiis (Ru., 23) [...] O segundo nível é o da fides: cum pietate et cum fide. [...] A pietas, no par que forma com a fides, não é nem menos formal nem menos ritual do que em seu primeiro nível, o do sacrifício. O perjúrio não é senão uma outra variante do sacrilégio. [...] O terceiro nível da pietas vai além da fides, abstração divinizada, noção política e social, e da lei do juramento. Ele se define pelos princípios do bem e do mal, pelos adjetivos bonus (innocens, innoxius), malus, scelestus, Isto é, por noções puramente éticas. ${ }^{21}$ (CHAMPEAUX, 1989, p.271-272)

Concordamos que em Rudens Plauto busca, por meio da representação do culto de Vênus, a correção de costumes que seriam em alguma medida prejudiciais ao convívio em Roma. Contudo, no corpo plautino esta preocupação não está dissociada da prática religiosa de modo que indicasse a possibilidade de uma pietas restrita ao convívio social. A personagem Palestra em seu lamento após o naufrágio chega a afirmar que o aceitaria de bom grado se tivesse sido ímpia para com os deuses ou para com os pais (PLAUTUS, Rudens, vv.6-8). O próprio cenário de Rudens, que se destaca dentre as comédias romanas pela sua riqueza de detalhes ${ }^{22}$, por sua vez, traz consigo a relação entre a ação

\footnotetext{
${ }^{19}$ Champeaux 1989, p. 270: "un système d'équivalences et d'oppositions précise et enrichit ces notions religieuses et morales : le pius y est opposé au scelestus et identifié à l'homme de bien, aux boni qui vivent cum pietate et cum fide, ceux qui ont la pureté du cœur et qui, seuls, peuvent obtenir la faveur des dieux. Pietas, pius, se chargent d'un sens nouveau. La pietas, traditionnellement entendue comme l'état de «bon rapport avec les dieux », se définit par la rectitude de l'intention, non plus par l'exactitude des gestes. L'homme « pieux » n'est plus seulement celui qui satisfait scrupuleusement aux rites; il est « celui qui respecte les valeurs morales »."

${ }^{20}$ SARAIVA, op.cit., 1069.

${ }^{21}$ Champeaux, ibid, pp. 271-272: "une étude des occurrences [...] de toute cette famille de mots, pietasimpietas, pius-impius, chez Plaute, permet d'y reconnaître trois formes — oserons- nous dire trois degrés? - de la pietas. L'une, sans conteste la plus primitive, est rituelle, formelle, sacrificielle. Elle tient tout entière dans le culte extérieur des dieux. C'est celle qu'évoquait l'étoile Arcturus : donis, hostiis (Ru., 23) [...] Le second degré est celui de la fides : cum pietate et cum fide. [...] La pietas, dans le couple qu'elle forme avec la fides, n'est alors ni moins formelle, ni moins rituelle qu'à son premier degré, celui du sacrifice. Le parjure n'est qu'une autre variante du sacrilège. [...] Le troisième degré de la pietas va au-delà de la fides, abstraction divinisée, notion politique et sociale, et de la loi du serment. Il se définit par les principes du bien et du mal, les adjectifs bonus (innocens, innoxius), malus, scelestus, c'est-à-dire par des notions purement éthiques".

${ }^{22}$ Cf. DUCKWORTH, Id., p.148.
} 
das personagens e o divino ${ }^{23}$, como destacou Jeppensen (2015, Plautus Rudens' and the worship of Venus):

O culto de Vênus é bastante proeminente em Rudens, uma vez que o santuário e o altar em honra à deusa estão representados em palco, desse modo, permitindo que a audiência avalie as atitudes das várias personagens em relação à deusa e, por sua vez, à observância religiosa de modo geral, por meio de seus comportamentos no santuário. $\mathrm{O}$ contexto de temas religiosos inicia-se com um prólogo divino apresentado pela estrela Arturo, que esboça um sistema religioso em que recompensas e punições são repartidas pelos deuses em conformidade com a moralidade das ações mortais, um contraste surpreendente à tradicional visão do ut des da prática religiosa do povo romano. Este sistema é então imediatamente colocado em ação, visto que Arturo explica como ele pune Labrax por cometer perjúrio provocando uma tempestade com o fito de destruir seu navio e trazêlo de volta ao santuário de Vênus para um acerto de contas. ${ }^{24}$

Podemos afirmar, portanto, que os vícios do desonesto Labrax e as virtudes do ancião Dêmones, por exemplo, eram constantemente comparadas pelo espectador do teatro à sua atitude para com a deidade. Na representação plautina, a pietas pode ser reconhecida como virtude religiosa e social de modo indissociável.

Passemos à singular religiosidade presente nos versos 257-258 de Rudens:

Quisquis est deus, veneror ut nos ex hac aerumna eximat 25 , miseras inopis aerumnosas ut aliquo auxilio adiuvet.

Quem quer que seja o deus, rogo para que nos livre deste sofrimento,

que favoreça estas miseráveis, desprovidas e infelizes com algum auxílio.

Após o retorno à praia das jovens escravas que conseguiram escapar do navio por intervenção da estrela Arturo, Palestra ora a uma divindade indeterminada. Recorde-se que o único apoio visual de que dispõe, na cena, é um templo distante cujo deus a que é atribuído se desconhece. Acaso podemos depreender a partir desse excerto que a prática religiosa na Roma helênica, em sua descrição cômica por Plauto, prescindiria de uma imagem? Poderia o Fatum, como abstração superior aos deuses, servir de base para o passo em análise? Diante da ausência de evidências textuais que elucidem tal

\footnotetext{
${ }^{23}$ Desde o prólogo da obra há o apontamento para uma representação do templo de Vênus em cena (Cf. PLAUTUS, Rudens, PROLOGVS, v. 62).

${ }^{24}$ JEPPENSEN, Seth A.. Plautus Rudens' and the worship of Venus in Dictating parody in Plautus Rudens. Didaskalia, n.12, 2015: "The worship of Venus is quite prominent in Rudens, since a shrine and altar to the goddess are depicted onstage, thus allowing the audience to evaluate the attitudes of the various characters toward the goddess, and in turn toward religious observance in general, by their behavior at the shrine. The foregrounding of religious themes begins with a divine prologue delivered by the star Arcturus, who outlines a religious system in which rewards and punishments are meted out by the gods according to the morality of mortal actions, a surprising contrast to the traditional do ut des view of Roman religious practice. This system is then immediately put into action as Arcturus explains how he punished Labrax for committing perjury by whipping up a storm in order to destroy his ship and return him to the shrine of Venus for a reckoning."

${ }^{25}$ As construções de petição ao deus são feitas por uma sucessão de orações nas quais há a conjunção $u t$ e um verbo no Presente do Subjuntivo (e.g. eximat, adiuvet) em períodos de consecutio temporum de ação concomitante.
} 
questionamento, optamos por nos ater a considerar o templo, por si só, como um dado visual suficientemente investido de religiosidade que possa sustentar, em cena, a prática religiosa socialmente compartilhada por seus espectadores a que Plauto parece aludir nesse passo.

Além das práticas exemplificadas anteriormente, há também em Plauto a presença de utensílios usados em sacrifícios no templo de Vênus, que podem ser observados no excerto a seguir, na fala do velho Dêmones:

\author{
semper petunt \\ aquam hinc aut ignem \\ aut vascula aut cultrum aut veru \\ aut aulam extarem, aut aliquid
}

sempre procuram por
água neste lugar ou por fogo
ou vasinhos ou cutelo ou espeto
ou pote de vísceras, ou outra coisa.
(PLAUTUS. Rudens, vv. 133-135)

Estes materiais sacrificiais são enumerados de modo que o espectador ou ouvinte possa visualizá-los, ao menos mentalmente, ainda que não saibamos de que maneira a peça foi encenada. Se, como tratamos, Plauto valia-se do cotidiano em sua dramaturgia, podemos afirmar que a representação destes objetos que constituem a religiosidade do sacrifício, prática comum no período helênico que, contudo, não é encontrada nas comédias de Terêncio ${ }^{26}$, não só é identificável no dia a dia dos espectadores como afirma a virtuosidade desta prática. É importante ressaltar que o provedor destes instrumentos em cena é o senex Dêmones, neste caso como figura honrada ${ }^{27}$, dotada de experiência, que os transfere, possivelmente, para pessoas mais jovens.

Voltemos a tratar do cenário como elemento dramático que relaciona a postura para com o divino e para com o outro. O reconhecimento do ambiente do mar como um elemento explorado por Plauto na composição da peça de modo a deixar transparecer a religiosidade evocada pela trama se encontra, por exemplo, no estudo de Sorba (2010, p. 26):

Os empregos de mare em Rudens fazem sobressair um retrato sêmico na apresentação da realidade extralinguística que é o mar essencialmente como um lugar, mais frequentemente perigoso, de pesca e navegação. A originalidade da presença dos pescadores, constituindo propriamente um coro (v. 290-305), o caracteriza em relação a outras peças: o mar e seus trabalhadores constituem um elemento concreto da cenografia e da intriga, e mare não faz simplesmente o papel de indicador geográfico - como o pode ser alhures - ou um elemento de comparação. A dualidade da representação do mar que sobressai do estudo de mare (a um só tempo nutriz para seus pescadores e sepulcro para os homens e seus bens) se

${ }^{26}$ Cf. Gellar-Goad (2013, p. 156-157).

${ }^{27}$ Moura (2005, p.22-23) ressalta os diferentes tratamentos de Plauto com relação ao senex: "encontramos nos autores a observação negativa dos males que a velhice traz na mesma medida em que encontramos a estima por eles do amadurecimento, nos senes, da mens, ratio e do consilium. Será justamente esta aparente ambiguidade no retrato do velho que contagiará comicamente as representações dos senes em Plauto, apresentados ora como respeitáveis, ora como ridículos". 
traduz de maneira original no Rudens pela apresentação ambivalente de seu deus tutelar (deus jocoso e vingador). ${ }^{28}$

O mar é elemento determinante no compasso da comédia situada na costa de Cirene. Na tentativa de Labrax transportar Palestra e Ampelisca para a Sicília, a fúria marítima evocada pela estrela garante o retorno das personagens (PLAUTUS, Rudens, vv.160182) para o ambiente em que o descobrimento de identidade, também originado no mar (Id., op. cit., vv. 1291-2), e libertação das meninas de nascimento livre se daria como podemos verificar no trecho a seguir:

\section{ego quoniam video virginem asportarier, tetuli ei auxilium et lenoni exitium simul}

Eu, ao ver a virgem ser levada embora,

Ao mesmo tempo, trouxe auxílio para ela e ruína para o rufião

(PLAUTUS. Rudens, PROLOGVS, v. 68-69)

Conforme observado por Sorba (2010), o mar, personificado pela divindade Arturo, tem papel central na comédia Rudens, como podemos verificar com maior precisão no excerto acima. O verbo video no Presente do Indicativo em voz ativa parece confirmar sua constância na ação cômica. Além disso, os vocábulos $e i$ e lenoni, respectivamente, Dativo de interesse positivo e negativo, são recursos de Plauto que reafirmam a divindade como detentora da recompensa para o pius e, também, da punição para o scelestus.

Reconhecidos tais dados a respeito da religiosidade romana em Plauto, pudemos depreender que a pietas era uma virtude considerada essencial para o cidadão romano e para a própria Urbs. O vir pius por meio de práticas religiosas visava a garantir o favor divino e cumprir seu dever coletivo. Por outro lado, a condição reprovável de um homem scelestus e impius na Roma helenística também é representada com precisão no corpo plautino. Apesar do fato de que, em geral, o romano cultuava divindades específicas, na representação plautina há casos divergentes (e.g. Rudens), que podem indicar influências de povos conquistados. Tais fatos, dentre outros, compõem esta investigação ainda em desenvolvimento e são pertinentes na delimitação de uma religiosidade romana frente aos contatos estrangeiros.

\section{Referências bibliográficas:}

\footnotetext{
${ }^{28}$ Sorba, J., 2010, p. 26: "Les emplois de mare dans la Rudens font ressortir un portrait sémique présentant la réalité extralinguistique qu'est la mer essentiellement comme un lieu, le plus souvent dangereux, de pêche et de navigation. L'originalité de la présence des pêcheurs, constituant même un chœur (v. 290-305), la caractérise par rapport aux autres pièces : la mer et ses travailleurs constituent un élément concret du décor et de l'intrigue, et mare ne joue pas simplement le rôle d'indicateur géographique - comme il peut l'être par ailleurs - ou d'un élément de comparaison. La dualité de la représentation de la mer qui ressort de l'étude de mare (à la fois mer nourricière pour les pêcheurs et mer tombeau pour les hommes et leurs biens) se traduit de manière originale dans la Rudens par la présentation ambivalente de son dieu tutélaire (dieu joueur et vengeur)".
} 
CHAMPEAUX, Jacqueline. « Pietas » : piété personnelle et piété collective à Rome. In: Bulletin de l'Association Guillaume Budé, n.3, octobre 1989. pp. 263-279.

DUCKWORTH, G. E.. The nature of Roman Comedy. Princeton: Princeton University, 1952.

FUNARI, P.P.A (org.). As religiões que o mundo esqueceu: como egípcios, gregos, astecas e outros povos cultuavam seus deuses. São Paulo: Contexto, 2009, p.6)

Roma: vida pública e vida privada. São Paulo: Atual, 1993.

GELLAR-GOAD, T.H.M.. Religious Ritual and Family Dynamics in Terence in Blackwell's Companion to Terence. New Jearsey: Wiley-Blackwell, 2013.

GRENIER, Albert. Le génie romain dans la religion, la pensée et l'art. Paris: Éditions Albin Michel. 1938.

HANSON, J. A.. Plautus and Roman religion. Baltimore: John Hopkins University, 1959.

JEPPENSEN, Seth A.. Plautus Rudens' and the worship of Venus in Dictating parody in Plautus Rudens. Didaskalia, n.12, 2015.

LEENHARDT, Jacques; PESAVENTO, S. J. (Org). Discurso histórico e narrativa literária. Campinas: Unicamp, 1998

MARTINS, Paulo. Literatura Latina. Curitiba: IESDE, 2009.

MOURA, F. M.. Análise tipológica do senex em Plauto: Periplectomenvs (Miles Gloriosvs) e Lysidamvs (Casina). Rio de Janeiro: UFRJ, 2005.

PEREIRA, M. H. R.. Idéias morais e políticas dos romanos. In: Estudos de História da Cultura Clássica. Lisboa: Fundação Calouste Gulbekian, 2002.

PLAUTUS, T. M.. Rudens. Disponível em:

<https://www.thelatinlibrary.com/plautus/rudens.shtml>. Acesso em: 29/01/20 às 22:52.

RILEY, H. T.. The comedies of Plautus. Londres: 1880.

RÜPKE, Jörg. Religious deviance in the roman world. Trad. RICHARDSON, D. M. B.. Erfurt: Universidade de Erfurt, 2016.

SARAIVA, F. R. dos Santos. Novíssimo dicionário latino-português. 3. ed. Rio de Janeiro: Garnier, 1927.

SCHEID, John. La religion des romains. 3. ed. Malakoff: Armand Colin, 1998. The gods, the state, and the individual: reflexions on civic religion

in Rome. Trad. Clifford Ando. Philadelphia: University of Pennsylvania, 2016. 
SORBA, Julie. Le vocabulaire de la mer dans la Rudens de Plaute in L'Information Grammaticale, n. 127, 2010. pp. 24-27.

TOLLIVER, H. M.. Plautus and the State Gods of Rome in The Classical Journal Vol. 48, No. 2. CAMWS, 1952, p.49-57.

VEYNE, Paul. L'hellénisation de Rome et la problématique des acculturations. Diogène, 1979, p.3-29. 